\title{
Learning to see: moral growth during medical training
}

\author{
Judith Andre Michigan State University, USA
}

\section{Author's abstract}

During medical training students and residents reconstruct their view of the world. Patients become bodies; both the faults and the virtues of the medical profession become exaggerated. This reconstruction has moral relevance: it is in part a moral blindness. The pain of medical training, together with its narrowness, contributes substantially to these faulty reconstructions. Possible improvements include teaching more social science, selecting chief residents and faculty for their attitudes, helping students acquire communication skills, and helping them deal with their own pain. Most importantly, clearer moral vision requires time and scope for reflection.

'A field of energies [converges] on us, shaping us, distending us, shattering us, and sending us on paths we have not chosen' (1).

With these words Richard R Niebuhr describes the suffering which leads to growth in faith, comparing it to a shipwreck which is followed by survival, amazement and gladness. Eventually the field of energies becomes friendly and supportive; one acquires 'consciousness of the stream of life, a sense of collectedness, ... a sense of effectiveness and of recognition as an agent ... an inner sense of motion' (2).

Many a medical student and resident would appreciate these metaphors. The beliefs and hopes which carried them to medical school often founder. Newcomers learn - they must learn - to see in different ways.

'Amazed gladness', however, does not always describe their new perspective. Some research suggests that students grow more cynical, less humanitarian (3), and more contemptuous of patients (4). Perceptions affect behaviour, and so, for instance, the increase in contempt toward patients corresponded with an increase in sarcasm directed at them.

In fact there has been a great deal of research recently on the effects of medical training. Although I will refer to a fair amount of it here, I do not really mean to endorse it. I do assume that some things go wrong, if only because medicine is a human institution

\section{Key words}

Moral development; medical education; professional-patient relationship. and as flawed as all the others. My purpose is to provide a different way of thinking about some of the good and bad things that happen.

For one thing I want to underline what Good and Good say, in work from which I will draw shortly: that new habits and attitudes are not simply 'picked up' or learned through reward and punishment. Rather, they are part of a restructuring of the world and the self (5).

In addition I want to sketch the moral relevance of these reconstructions. Some of them count as moral growth, some as regression.

'Moral growth' is a looser term than Lawrence Kohlberg's 'moral development' . 'Development implies an invariant, necessary, universal sequence of stages; what I have to say implies none of that. Kohlberg alse focused solely on progress in moral judgement: the resolving of ethical conflicts through (at the highest stage) universal principles. In contrast, here I develop a point first made by James Rest (6), who notes that moral behaviour involves more than thinking about conflicts: one must first recognise that a conflict exists.

One aspect of moral development, then, is vision: an increasing ability to see the moral landscape (7). Here I'll talk about two central objects of moral perception: 1) the intrinsic value of individuals; 2) the value and the danger of institutions.

\section{The moral landscape}

Students bring an idealised picture to medical school, one that cannot survive. Students soon begin reconstructing that picture, partly to make room for all they are learning, partly to protect themselves from pain. In some ways this new, more realistic picture provides clearer moral vision. In other ways it does not.

\section{PATIENTS}

Medical students probably begin by thinking of patients as people who have physical problems, and who are curable, who co-operate with the cure and are grateful for it.

The preclinical years begin to redraw that picture, partly by adding enormous amounts of physiological data, partly by slighting other kinds of data. Case descriptions contain 'minimal social and personal characteristics and great physiological detail'. In anatomy lab students 
'began to experience people differently ... . In normal reality, the body surfaces - the skin, the hands the eyes, the face - convey personhood. The interior of a person is his or her thoughts, experiences, personality'.

But in the lab, the interior is tissue, cells, organs. This new world is a 'physical world, a complex threedimensional space, a thing of compartments, tubes, and electrical system' (8).

In addition the doctors-to-be must leave behind their intense emotional responses to suffering and pain; they must develop what Renee Fox and Harold I Lief call 'detached concern': an 'awareness of enough separateness from the patient so that expert medical skills can be rationally applied' and equanimity be maintained (9).

Furthermore, the patient is relatively ignorant, with a set of concerns very different from the doctor's, sometimes trivial (say, fear of an injection), sometimes the temporary result of pain or worry. Even the clinician most interested in the patient-as-person can feel impelled to bracket what the patient-at-thepresent-moment believes and chooses. When the patient is inarticulate, uneducated, or from a different culture, the barriers between him or her and the doctor can become insuperable.

Worse, the patient can be a threat - to the doctor's sense of accomplishment or need to be liked or simply his sleep (10). Or a threat to her need to learn: the ideal patient comes to be the interesting case, and interesting is defined in terms of complex physical illness (11).

So by the end of medical training patients can seem to be ignorant companions - or even enemies. Even the best of them can slip from centre-stage to the wings (12): like the owner of an automobile, who can ruin a mechanic's good work, she needs to be kept happy for the sake of the car.

In other words, some aspects of medical training can make it harder to see, in a morally effective way, the patient as a person. This is not to say that no doctors manage it; of course they do, and those who do not learn it during training may develop it later. But there is an intrinsic tension between the necessary objectivity of medical training and attending to the patient's subjectivity. My purpose is to point out the danger and consider ways of lessening it.

\section{THE INSTITUTIONS OF MEDICINE}

The entering student might picture medical school as highly demanding, but necessarily so, and medicine as forbiddingly complex but full of certainty. Teaching hospitals seem to be dedicated to the welfare of the patient, and to be ideal places to learn medicine. Nurses are compliant and admiring assistants; no other health care professionals exist.

This picture, too, must change. The first years of school are indeed demanding - many think unreasonably so. Some students become convinced that much of their time is being wasted (13).
In the clinical years students lose their illusions about the teaching hospital. Some medical personnel are incompetent. The hospital uneasily juggles care of patients with research and teaching needs.

Finally, medicine itself - as a body of knowledge - is probably more limited than they expected.

Moral vision as I use the term here includes realism about institutions: an active appreciation combined with scepticism. The novice doctor must decide which rules to keep, which to ignore and which to try to change; must be ready for the mistakes of those around him, yet keep clearly in mind how much he depends on their steady good work. This is a fine line to walk, and failures are not surprising.

One possible failure is cynicism: contempt toward the hospital and (some of) its services, as if they are merely defective levers to be manipulated. A different kind of failure exaggerates virtues, particularly of medicine as students have been taught to practise it. Decisiveness, for instance - a necessary attribute - can extinguish appropriate doubt. The 4th-year student overestimates the certainty of experimental results, the reliability of tests, and the likelihood of disease (14). A chief resident transmits her best guesses to the patient as more certain than they actually are. Melvin Konner talks about one of the common-sense rules of medicine: 'If you don't know what to do, don't do anything', and about how hard it is to keep that rule (15).

Furthermore, novice doctors absorb the general lack of corporate responsibility within medicine. As Eliot Freidson pointed out years ago, the only ordinary sanction is a lack of referrals and consultations (16).

Newcomers to medicine, then, must build new understandings of its institutions. Sometimes the new picture exaggerates strengths or weaknesses.

\section{Two obstacles to clear sight}

Many things interfere with seeing clearly, from the quantity of physiological information to the examples set by others. Here I will focus on two which receive relatively little attention: pain, and the lack of time.

\section{PAIN}

Pain makes it hard for one to look outside oneself, and distorts what one sees (17). Medical students and residents may suffer profoundly. All the clinical years, and especially the internship year, are times of stress, anxiety, depression, threatened self-esteem and anger (18).

Some of this is inevitable. Part of growing up is learning how powerful, alien, and random the world can be. It hurts to confront pain when one can offer no help. It can also hurt to confront oneself: to recognise, for instance, a sudden desire to punish someone.

But not all the suffering of medical training is necessary. Nurses' training, for instance, seems to be a fairly different experience (19). If some of the pain during medical training is unnecessary, it is something for which we all pay a price, in the diminished moral and clinical understanding which results: 
'A resident, like others faced with threats to selfesteem, may feel compelled to ... associate himself with what he considers good and repudiate what he believes is bad. This process may be manifest as arrogance, depression, idealisation of or contempt for other health professionals or as correspondingly extreme attitudes toward patients. Any of these ... may interfere with work, thus adding to the resident's need to bolster his self-esteem ...' (20).

Finally, repressed anger and sadness can result in errors in diagnosis and treatment (21).

\section{TIME, SPACE, AND THEIR ABSENCE}

The sometimes desperate lack of time during medical training has a number of consequences for moral perception. One is simple, obvious, but nevertheless important: people working under great time pressure are less likely to notice someone needing help (22). More subtly, others come to be seen as consumers of time - the scarcest of commodities (23). But the deepest way, I think, in which a lack of time interferes with moral perception is that it allows so little reflection.

Reflection is crucial to moral vision. Reflection consists, partly, in seeing (into) oneself: it involves paying attention to nagging doubts, finding words for convictions, articulating feelings; it requires time and quiet. Reflection is less orderly and less discursive than reasoning. It is helped by leaving one's usual sphere, physically going away or just reading and talking in venturesome ways.

Medical training makes all of this hard. Students and residents are always overwhelmed with work and frequently exhausted. Their world is physically, emotionally, and intellectually circumscribed.

What makes it still narrower is that the circle of those with cognitive authority is so tightly drawn. Chance encounters with those offering a different perspective will yield little fruit, if those people are discounted as outsiders. One purpose of any initiation rite - and medical school is in some ways one long initiation rite - is to separate one group from the rest, and bond its members through shared ordeals and secrets. (Konner, an anthropologist who later went through medical school, remarked on the necessary comfort provided by 'ritualistic routines' (24).)

Reflection is a precursor to discursive thinking; it is the stage which allows half-perceived problems to be fully seen. And it is difficult during the long years of medical training.

The suppressed pain in medical training, then, and its devouring of time, both interfere with moral vision.

\section{Learning to see}

My primary purpose in this essay is to point out the intricacy and the moral importance in forming new perspectives. I will make some specific suggestions, but hope that others make many more. I only want to begin the discussion. My own suggestions include more training in the social sciences (to balance the physiological information); some changes in the structure of training (since what we experience affects our sense of what is possible); help in dealing with psychological pain; and time off.

\section{SOME HELP FROM THE SOCIAL SCIENCES}

The professional with moral understanding sees the patient as a person. Just as we tend to assume that 'caring' is innate and cannot be learned - a selffulfilling prophecy (25) - we tend to forget that seeing is a skill. Babies practise seeing, and adults can learn to see what they had never noticed before. Noticing another's subjectivity is a skill that can be learned (26). Communication skills, for instance, entail a kind of perception, partly because listening is half of communication, but also because effective talking (explaining, exhorting) demands constant awareness of whether the patient understands.

The moral professional also sees institutions for what they are: enabling but also at times oppressive. Much of what she needs for this is found in the social sciences. Some examples: economics finds that professionalisation is a move toward social privilege and control; history reminds us of the Tuskegee syphilis experiments; sociology tells us that no practitioner is self-made or practises in a vacuum.

Some of the findings of psychology contribute to self-reflection. For example: Milgram's findings that most of us are willing to hurt other people if ordered to; the findings that the presence of others makes any one individual feel less responsible; the indications that individuality in such small things as dress and hairstyle help maintain a sense of individual responsibility (27).

\section{THE STRUCTURE OF MEDICAL TRAINING}

Institutions shape perception: they make some things visible, they mark things as important; they show what is possible.

When Lawrence Kohlberg worked with prisoners, he found that many had never lived in a co-operative, helpful environment. They did not know that such a situation could exist. Kohlberg had gone to the prisons to help the prisoners develop higher levels of moral reasoning. When he realised how much their harsh backgrounds affected their thinking, Kohlberg tried to create for them - and later for high school students 'just communities'. Experience provides a kind of knowledge nothing else can.

What are the implications for medicine? Fundamentally, and simply, that we pay attention to the structure within which students and residents learn. To begin with, we know that most medical schools are highly selective and that many students spend intensely competitive undergraduate years. Competition can stimulate quality work, but it can also turn people against one another. Interestingly enough, James $\mathrm{H}$ Bryan found that college students learn more [my emphasis] when 'grades are assigned not on 
individual merit but on group performance'. This is apparently a result of 'an increase of co-operation ... sharing of materials and ideas' (28). What is more important in medical school: stimulating and evaluating individual effort, or fostering co-operation? Why? Even a discussion of these issues, with no change in environment, can help stimulate reflection about what the initiation experience is all about.

During clerkships students confront their first fleshand-blood ethical problems, and sometimes must participate in treatment they deeply oppose. The pressure for grades at this time is especially intense, since the subjective evaluations of their superiors count for so much. Ethics clerkships - weekly meetings in which cases are presented confidentially, attendance is required, but grades are not given - support students in their independent evaluations, even if they are unable to carry out their convictions (29). If nothing else, such sessions help people deal with frustration and that should lead to calmer thinking.

Many others have pointed out the importance of the clinicians with whom a trainee works. They provide reward and punishment, and embody a way of practising: of using time, of talking with patients, of making decisions. The more powerful they are and the more they enjoy their work, the more influential their example (30). The selection of chief residents and attendings would ideally take this into account.

\section{DEALING WITH THE PAIN}

What would lessen the pain that obscures moral vision? Some of it could just be gotten rid of: students need not be yelled at, insulted, or humiliated. They need not be so savagely sleep-deprived. They need not be put in situations far beyond their competence, or on the other hand have so much of their time wasted. Some of the structural double-binds in which students find themselves could be changed through a change in the curriculum. Rosenberg puts it this way: the attributes for which students have been chosen will almost inevitably serve to frustrate them. Chosen for a history of academic success, they face predetermined failure (there's too much to learn); independent learners, they face a rigid, rote curriculum; wanting to serve patients they must first learn technology and jargon. And chosen for their independence, they are (in the United States at least) deeply in debt (31).

A change in public expectations would help, too. Some of the pressure from patients - Do something! Find out what's wrong! - would ease if doctors educated the public about the limitations of medicine. But this is unlikely to happen soon.

Institutions change slowly. While we are waiting, more piecemeal things can be done. Programmes to help students face their own pain, express it, and thus deal with it have met with at least temporary success. These have included seminars for residents on the doctor-patient relationship which focused on pain, on dying, and on the difficult patient (19), periodic sessions throughout internship which included discussion, role-playing, problem solving, presentations, readings, and films. Of one such session an intern wrote:

'This was truly the most comforting session for me - to see people I respect admit their own mistakes. I have used what I learned or experienced there all year long ... . My behaviour has been altered in that often, when I make mistakes, I can forgive myself and continue doing the best I can' (32).

It seems to be important that these programmes include time away from the hospital, and include meals and socialising. If the programmes just add to the student or resident's schedule, they will be rejected (33).

The success of any one intervention can be diluted and lost. Change needs to be pervasive - and probably needs to include basic changes in the practice of medicine itself, for training years do not exist in isolation: they are meant to prepare people for a profession practised in a certain way.

Still, when enough pieces of an institution change, the whole has changed. Incremental change is the normal, and perhaps the safest, method of progress. Which is to say that all of these projects, it seems to me, are worth trying.

\section{Conclusion}

Youthful idealism cannot last. This is as true in medicine as in a monastery, the military, or the ballet. What replaces young dreams is, one hopes, a deeper understanding. A clearer, more sympathetic and more critical view of the world is a crucial element in moral growth.

We must find the materials that will help students and residents develop an understanding of patients as persons: complexly biological but always more than that; not always co-operative, not always fixable, but always the centres of their own lives. We must also find a way to help new doctors see medicine as a social institution, neither glorious nor corrupt.

Of all the suggestions I've made here, the one I would emphasise most is a less all-consuming institution of training: schools and residencies which allow the time and distance for independent moral thought.

\section{Acknowledgement}

I was supported while working on this paper by the Harvard Program in Ethics and the Professions, Old Dominion University, and a Rockefeller Foundation Fellowship from the Institute of Medical Humanities at the University of Texas Medical Branch. I profited particularly from frequent discussions with Greg Dees, Lachlan Forrow, David Wasserman, and Dan Chambliss. Letha Cole provided an invaluable psychiatric perspective, and Tom Cole helpful, detailed editorial advice. 
Fudith Andre is Associate Professor at the Center for Ethics and Humanities in the Life Sciences, and in the Department of Philosophy, Michigan State University, East Lansing, Michigan, USA.

\section{References and notes}

(1) Niebuhr R R. Experiential religion. New York: Harper and Row, 1972: 78.

(2) See reference (1): 103.

(3) The classic studies were done by Eron L D. See: Effect of medical education on medical students' attitudes. Fournal of medical education 1955; 30: 559-566 and The effect of medical education on attitudes: a follow-up study. Fournal of medical education 1958; 33, supp: 2533. See also Rezler A G. Attitude changes during medical school: a review of the literature. Fournal of medical education 1974; 49: $1023 \mathrm{ff}$; and Bloom S W. Socialization for the physician's role: a review of some contributions of reserach to theory. In: Shapiro E C, Lowenstein L M, eds. Becoming a physician. Cambridge: Ballinger, 1979: 30. Eron's scale derives from the Levinson-Sanford scales of authoritarianism. Cynicism is defined as 'a contemptuous disbelief in man's sincerity of motives or rectitude of conduct, characterized by the conviction that human conduct is suggested or directed by self-interest or self-indulgence'.

(4) Kramer D, Ber R, Moore M. Impact of workshop on students' and physicians' rejecting behaviours in patient interviews. Fournal of medical education 1987; 62, 11: 904-905.

(5) DelVecchio Good M, Good B J. Disabling practitioners: hazards of learning to be a doctor in American medical education. American journal of orthopsychiatry 1989; 59, 2: 303-309.

(6) Rest J R. A psychologist looks at the teaching of ethics. Hastings Center report 1982 Feb: 29-36.

(7) Throughout the paper I use various visual metaphors: vision, seeing, perception, and so on. I use them interchangeably.

(8) See reference (5).

(9) Lief H I, Fox R C. Training for 'Detached Concern' in medical students. The psychological basis of medical practice. New York: Harper and Row, 1963.

(10) This lack of empathy may carry over into private life. R D Cox found that 'physicians demonstrate an absence of depression or anxiety in those stressful situations, both within and outside of work, in which these affects would be expected ... [and] frequently seemed unable to empathize with members of their own families'. Cox concluded that this reaction was in substantial part a response to constant exposure to suffering. Nadelson $\mathrm{C}$ C, Notman M T, eds. Adaptation to stress in physicians: 204, citing Cox R D. Youth into maturity. New York: New York Mental Health Materials Center, 1970.

(11) See reference (3): Bloom: 31.

(12) Cf Charles Bosk: 'I do not take the point of view of the patient since the occurrence of error is usually concealed from him and since he does not enter the interactions which surround social control. However lamentable the fact, the patient is an exogenous variable falling outside the system of social control'. Forgive and remember. Chicago: University of Chicago Press, 1979: 24-25.

(13) This was a major finding of Howard Becker in Boys in white, Chicago: University of Chicago Press, 1961; coauthors Blanche Geer, Evertee C Hughes, and Anselm L
Strauss. Bosk documents the same attitude during surgical residency.

(14) My evidence for this is anecdotal only. Although friends remember coming across research supporting my claim, I have been unable to track it down.

(15) Konner M. Becoming a doctor. New York: Viking, 1987: 364-366.

(16) Freidson E. Profession of medicine: a study of the sociology of applied knowledge. New York: Dodd Mead, 1970.

(17) Furthermore, 'people who are in a good mood (from remembering pleasant memories, from a recent success experience, from being given something) usually are more positive, generous, and willing to co-operate'. See reference (22): Rest: 565 .

(18) Butterfield P S. The stress of residency. Archives of internal medicine 1988; 148: 1429.

(19) I base this on anecdotes and observations, but also on Eron's research. He found that during training nurses grow less cynical, although also less humanitarian. See reference (3): 563.

(20) See for instance Sledge W H, Lieberman P B, Reiser L $\mathrm{W}$. Teaching about the doctor-patient relationship in the first postgraduate year. Fournal of medical education 1987; 62: 187-189.

(21) Herzog D B, Wyshak G, Stern T A. Patient-generated dysphoria in house officers. Fournal of medical education 1984; 59: 870.

(22) Rest J. Morality. In: Mussen P H, series ed. Handbook of child psychology: volume III: cognitive development. New York: John Wiley and Sons, 1983: 570. The research cited here concerned children. I am speculating that it also applies to adults.

(23) Rosenberg P P. Catch 22 - the medical model. In: Shapiro E C, Lowenstein L M, eds. Becoming $a$ physician. Cambridge: Ballinger, 1979: 90-91.

(24) See reference (15): 364-366.

(25) Cf reference (5): 305, and reference (9): 234.

(26) In Rhode Island Hospital, for instance, residents roleplay conversations with patients, and some of the conversations are videotaped. Behavioural scientists try to help the students communicate more clearly and sensitively. Arnold R M, Forrow L, Wartman S A, Teno J. Teaching clinical medical ethics: a model programme for primary care residency. Fournal of medical ethics 1988; 14: 91-96. See also reference (23): Werner E R, Korsch B M. Professionalization during pediatric internship: attitudes, adaptation, and interpersonal skills.

(27) Kelman H C, Hamilton V L. Crimes of obedience. New Haven: Yale University Press, 1989: ch 13.

(28) Bryan J H. Children's cooperation and helping behaviours. In: Hetherington E M, ed. Review of child development research vol 5. Chicago: University of Chicago Press, 1975: 144-181.

(29) I base this on experience with such clerkships at the University of Texas Medical Branch at Galveston.

(30) See reference (28): 150, 155, 174.

(31) See reference (23): 84 .

(32) Matthews D A, Classen D C, Willms J L, Cotton J P. A program to help interns cope with stresses in an internal medicine residency. Fournal of medical education 1988 ; 63: 539-547; 545 in particular.

(33) Girard D E, Sack R L, Reuler J B et al. Survival of the medical internship. Forum on medicine 1980; 3: 460-463, quoted and cited by Butterfield P S. The stress of residency. Archives of internal medicine 1988; 148: 1434. 